\title{
Concentrations of nutritional and trace elements in needles of Norway spruce (Picea abies [L.] Karst.) as functions of the needle age class
}

\author{
A. Wyttenbach ${ }^{1}$, P. Schleppi ${ }^{2}$, L. Tobler ${ }^{1}$, S. Bajo and J. Bucher ${ }^{2}$ \\ ${ }^{1}$ Paul Scherrer Institute, CH-5232 Villigen PSI, Switzerland and ${ }^{2}$ Swiss Federal Institute for Forest, Snow and \\ Landscape Research, $\mathrm{CH}-8903$ Birmensdorf, Switzerland
}

Key words: needle age class, Norway spruce, nutrients, Picea abies, trace elements

\begin{abstract}
The endogenous concentrations of the essential elements $\mathrm{Ca}, \mathrm{Cl}, \mathrm{Cu}, \mathrm{Fe}, \mathrm{K}, \mathrm{Mg}, \mathrm{Mn}, \mathrm{N}, \mathrm{P}$ and $\mathrm{Zn}$, and of the nonessential elements $\mathrm{Al}, \mathrm{As}, \mathrm{Ba}, \mathrm{Br}, \mathrm{Co}, \mathrm{Cr}, \mathrm{Cs}, \mathrm{Hg}, \mathrm{I}, \mathrm{La}, \mathrm{Na}, \mathrm{Rb}, \mathrm{Sb}, \mathrm{Sc}, \mathrm{Si}$ and $\mathrm{Sr}$ were determined in 5 successive needle age classes. 40 mature spruce trees from 6 different sites were investigated individually. A given element usually shows smooth changes with the needle age class $t$. Trees on a given site usually have a similar dynamic behaviour. The same holds for the different site means. The concentrations can be approximated by functions $c=f(t)$. Three different types of functions are required to describe the dynamic behaviour of 3 groups of elements that increase with $t$, and one for the elements that decrease with $t$. A given element usually can be described by the same type of function at all sites, even if its concentration differs widely. Exceptions are $\mathrm{Mn}$, Co and $\mathrm{Zn}$, which change from a decreasing function at low concentrations to an increasing function at high concentrations. Further irregulatities are found at some sites with $\mathrm{Ca}, \mathrm{Sr}$ and $\mathrm{Ba}$. These findings are corroborated by a multivariate statistical analysis.
\end{abstract}

\section{Introduction}

Norway spruce keeps its needles for several years. It is well known that elemental concentrations in needles change with the needle age class (Cape et al., 1990; Fiedler et al., 1973; Mahendrappa et al., 1986). Therefore many workers consider not only age class 1, but also one or more higher classes, presenting the results as graphs or tables. Very little effort has been made up to now to quantify these changes by algebraic equations. Usually, measurements are restricted to a few major nutritional elements; additional information from the same samples on minor or trace elements is mostly missing. Moreover, in general mixed samples coming from several trees are analysed. They give no information about changes in individual trees. It may therefore be stated that there is little systematic, quantitative information on the phenomenon of the change of concentration with needle age class. The present work was undertaken to clarify some pertinent aspects, specifically:
1) Can these changes be described by simple algebraic functions that relate the concentration to the age class?

2) If such functions (which we will call biodynamic functions) exist, how do they depend on the concentration level or the availability?

3) Does every element behave differently or are there groups of elements that can be described by the same type of function?

It is expected that the use of algebraic functions to describe concentration changes with time will in the end give a more quantitative description of the processes involved, such as uptake, storage and remobilisation. The functions should also be helpful in working out similarities or dissimilarities between the individual elements.

With Norway spruce, it is possible to collect at one date needle samples differing in age by multiples of one year. As average availability of elements for a given tree can generally be considered relatively constant from year to year, the difference in concentrations between samples from one branch will be mainly due to their different age. It should thus be possible to get 
a clear picture of concentration changes as a function of time for that tree. Repeating these experiments with different trees and at different sites will then show to what extent the pattern of the changes is universal.

\section{Methods}

Spruce trees ( $P$. abies) with an age of 50 to 250 years were sampled once by taking branches in the upper third of the crown in November. Twigs were cut to separate the needle age classes (usually 5 , but at a few sites only 3 or 4 ). One age class from one tree was then treated as an individual sample. Contaminations on the needle surface (soil particles and aerosols) were removed by washing with toluene and tetrahydrofuran (Wyttenbach et al., 1992). Twigs were dried, the needles were separated from the axis, and ground.

Elemental analysis of the needles was done by

a) instrumental neutron activation analysis for the trace elements $\mathrm{Al}, \mathrm{As}, \mathrm{Ba}, \mathrm{Br}, \mathrm{Co}, \mathrm{Cr}, \mathrm{Cs}, \mathrm{Cu}$, $\mathrm{Fe}, \mathrm{La}$, and the rare earth elements, $\mathrm{Na}, \mathrm{Rb}, \mathrm{Sb}$, Sc, Zn (from $0.1 \mathrm{ng} \mathrm{g}^{-1}$ to $100 \mu \mathrm{g} \mathrm{g}^{-1}$ ), and for the macroelements $\mathrm{Ca}, \mathrm{Cl}, \mathrm{K}, \mathrm{Mn}, \mathrm{Si}$ (Wyttenbach et al., 1992). The trace elements $\mathrm{Hg}$ and I could be determined only in a reduced number of samples (Tobler et al., 1994).

b) ICP-AES for $\mathrm{Ba}, \mathrm{Ca}, \mathrm{K}, \mathrm{Mg}, \mathrm{Mn}, \mathrm{P}, \mathrm{Sr}$.

c) Combustion analysis for $\mathrm{N}$ and $\mathrm{C}$.

Experimental analytical reproducibility varied with the element. It was about $2 \%$ for macroelements and some trace elements, but deteriorated to $20 \%$ for unfavorable trace elements at low concentrations. All results are reported with respect to needles dried at $85^{\circ} \mathrm{C}$, and are for endogenous concentrations only. The mean weight of a needle was determined in each sample by weighing 100 needles.

Six sites in Switzerland and south-western Germany over different bedrocks were sampled in the attempt to get a wide variation in the elemental concentrations in the needles. At every site from 5 to 9 trees were sampled. Different sites are sampled to get access to different concentrations; since at the present stage of the work no attempt is made to relate needle concentrations to soil or site properties, the sites will be referred to only by 3 letter acronyms.

Statistical calculations were done by SAS. The iterative approximation of nonlinear equations to the experimental data was done by the Gauss-Newton method. In Equations 2 to $6, c_{t}$ is the concentration of age class $t$. All other parameters are constants which are characteristic for a given tree or a given site. Current year's needles are defined as age class 1 .

\section{Results}

\section{Individual trees and site means}

With most elements, individual trees at a given site show a considerable variation of the concentration even within the same age class. The spread of the values, expressed as the coefficient of variation $\mathrm{CV}$, is usually between 10 and $30 \%$, but in extreme cases (such as Cs) CV can go up to $75 \%$, clearly indicating that the distribution is not normal. However, close inspection of the values of one element at a given site shows that all trees follow the same dynamic pattern, although at different concentration levels. In order to remove this effect, the following procedure was adopted:

The measured values from each tree are normalized to the tree level by

$$
\mathrm{c}_{\mathrm{t}, \mathrm{i}}^{*}=\mathrm{c}_{\mathrm{t}, \mathrm{i}} / \Phi_{\mathrm{i}}
$$

where $\mathbf{t}=$ age class, $\mathrm{i}=$ tree number, $\mathrm{c}=$ measured concentration, and $\Phi=$ mean of all measured values for a given tree. Site means and their standard errors for a given age class are calculated in the usual way using the normalized $\mathrm{c}^{*}{ }_{\mathrm{t}, \mathrm{i}}$ values. These normalized means and errors are then retransformed into concentrations by multiplication by $\Omega$, which is the mean of all measured concentrations from that site. Retransformed means are practically identical to those obtained directly from the $c_{t, i}$ values. Retransformed standard deviations and errors, however, are greatly reduced, usually by between 3 to 4 times. An example is given in Table 1 .

This reduction of errors is important for judging the significance of the changes that occur between the different age classes, and for choosing the appropriate function to describe these changes. In the example of Table 1, the site means suggest a continuous decrease of the $\mathrm{K}$ concentration with increasing $\mathrm{t}$, but the variation between the individual trees $(\mathrm{CV}=16 \%)$ is so great that the decrease is statistically not significant after $t=2$. The same holds for $P$ and $R b$, where $\mathrm{CV}$ is $28 \%$, and $35 \%$ respectively on average within each age class. Working with the normalized concentrations, however, shows that the decrease is indeed real. Throughout this paper reduced errors will therefore be used. Factors contributing to the reduced SD 
Table 1. Mean and standard error of $\mathrm{K}, \mathrm{P}$ and $\mathrm{Rb}$ in successive needle age classes $\mathrm{t}$ at site $\mathrm{REG}$ ( $\mathrm{n}=8$ trees)

\begin{tabular}{|c|c|c|c|c|c|c|c|c|c|c|c|c|}
\hline \multirow{3}{*}{$\begin{array}{l}\text { Data } \\
\text { treatment }\end{array}$} & \multicolumn{6}{|c|}{$\mathrm{K}\left(\mu \mathrm{g} \mathrm{g}^{-1}\right)$} & \multicolumn{3}{|c|}{$\mathrm{P}\left(\mu \mathrm{g} \mathrm{g}^{-1}\right)$} & \multicolumn{3}{|c|}{$\mathrm{Rb}\left(\mu \mathrm{g} \mathrm{g}^{-1}\right)$} \\
\hline & I & & & II & & & $\overline{\text { II }}$ & & & II & & \\
\hline & $\mathrm{x}$ & SE & (a) & $\mathrm{x}$ & $\mathrm{SE}$ & (a) & $\mathrm{x}$ & SE & (a) & $\mathrm{x}$ & $\mathrm{SE}$ & (a) \\
\hline$t=1$ & 6595 & 354 & A & 6603 & 69 & A & 1435 & 104 & A & 6.28 & .14 & A \\
\hline 2 & 4932 & 258 & B & 4944 & 92 & B & 1002 & 70 & B & 2.75 & .07 & B \\
\hline 3 & 4207 & 265 & B & 4201 & 83 & $\mathrm{C}$ & 891 & 47 & $\mathrm{C}$ & 2.01 & .06 & $\mathrm{C}$ \\
\hline 4 & 4024 & 240 & B & 4017 & 42 & $\mathrm{CD}$ & 873 & 32 & $\mathrm{C}$ & 1.85 & .06 & $\mathrm{C}$ \\
\hline 5 & 3900 & 245 & B & 3890 & 51 & $\mathrm{D}$ & 831 & 112 & $\mathrm{C}$ & 1.80 & .06 & $\mathrm{C}$ \\
\hline Site mean & 4731 & & & 4731 & & & 1010 & & & 2.94 & & \\
\hline
\end{tabular}

${ }^{*}$ Data treatment I-none, II-normalisation and retransformation (see text).

(a) Duncan's multiple range test, $\alpha=0.01$. Mean with the same letter are not significantly different.

are: errors in sampling and in sample preparation; analytical errors; and the deviations of the individual trees from an uniform dynamic behaviour. In the examples given, the individual trees follow a common pattern very closely. The reduced $\mathrm{CV}$ is $4 \%$ for $\mathrm{K}$ and $8 \%$ for $\mathrm{P}$ and $\mathrm{Rb}$ on average within each age class, part of which is due to experimental errors. Reduced concentrations are also used to decide if at a site one tree shows a dynamic behaviour that differs significantly from the other trees.

\section{Biodynamic functions}

For each element and site, a check was made whether the means of successive age classes could be described by a function $c=f(t)$. When there were several possibilities, the simplest function was retained, even if this in some cases implies a certain oversimplification. For most elements at most sites such functions could be found, and it was also found that several elements can be described by the same type of function, although with different constants. In the following these groups of elements will be treated together.

\section{Linearly increasing elements}

The concentration of many elements are found to increase proportionally to the needle age class,

$$
c_{t}=B \cdot t
$$

where $B$ is the mean yearly increment. Two examples are given in Figure 1. The function fits the experimental data well. It should be noted that the same function,

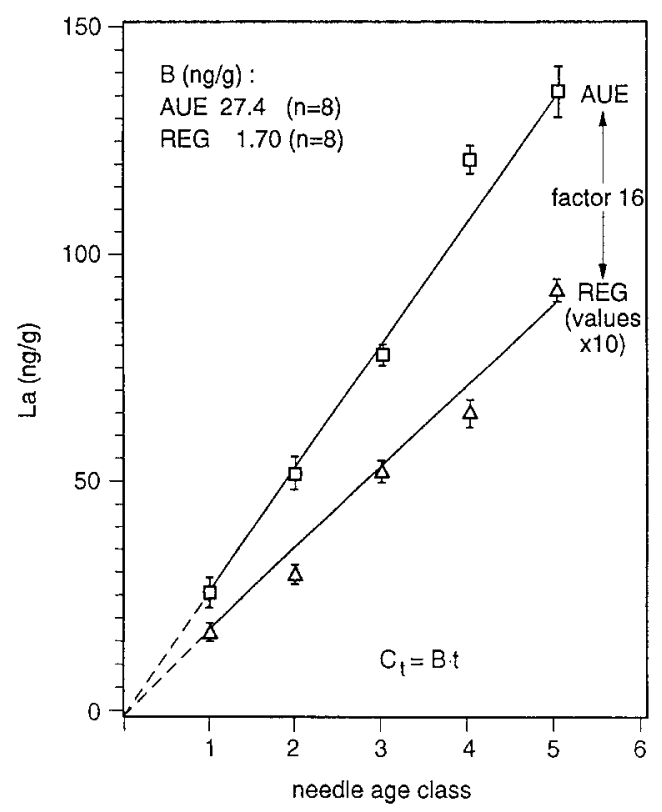

Fig. . The concentrations at the two sites with the smallest and the largest values. Points ate experimental sites means, errors bars denote the reduced standard error. The line is the fit of Equation 2. The mean deviation (experimental-predicted) is $7 \%$. All values for the lower site have been multiplied by 10 for an easier presentation.

although of course with a different $B$, applies at all concentration levels. The same type of function as with $\mathrm{La}$ is also found with $\mathrm{Si}, \mathrm{Sb}, \mathrm{Sc}$, all rare earth elements, and on some sites with $\mathrm{Na}$. 


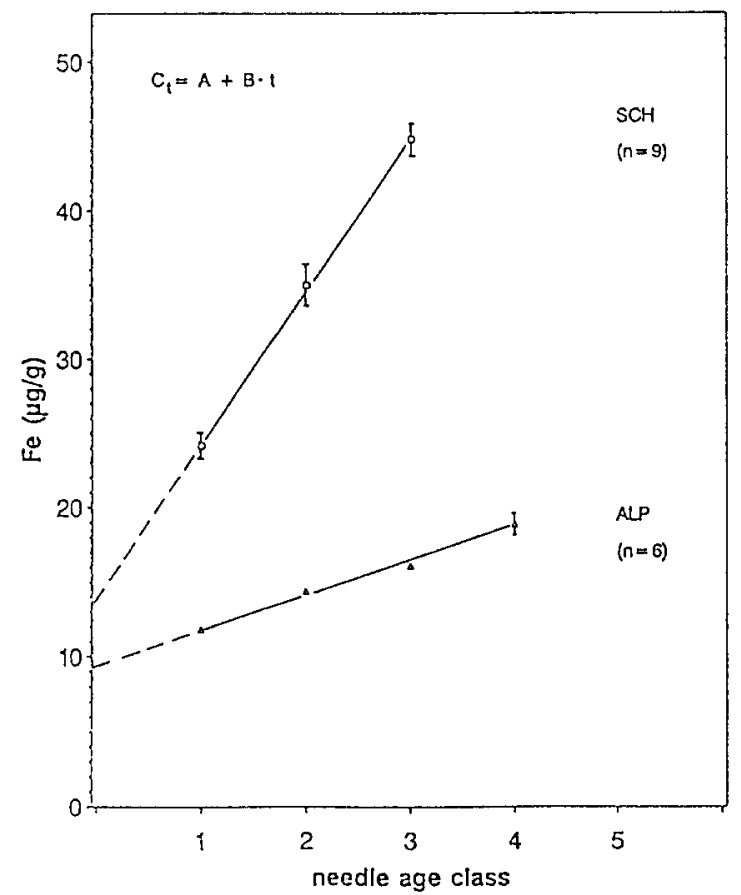

Fig. 2. Fe concentrations at the two sites with the smallest and largest values in class 1. The line is the fit of Equation 3. The functions are, with $\mathrm{A}$ and $\mathrm{B}$ in $\mu \mathrm{g} \mathrm{g}^{-1}: \mathrm{c}_{\mathrm{t}}=10.4+13.3 \cdot \mathrm{t}$ at $\mathrm{SCH}$ and $c_{t}=9.4+2.3 \cdot t$ at ALP.

Linearly increasing elements with an excessive accumulation in age class 1

Another behaviour is shown by $\mathrm{Fe}, \mathrm{Al}, \mathrm{As}, \mathrm{Hg}, \mathrm{Br}$ and I. Similar to La, these elements also show a steady increase with $t$, but the extrapolated line clearly does not pass through the origin. The appropriate function therefore is

$$
c_{t}=A+B \cdot t
$$

Figure 2 gives the data for $\mathrm{Fe}$ at two sites. No clear relation between $A$ and $B$ could be found when considering the data of all sites, indicating the $\mathrm{Fe}$-concentration at $t=1$ is a poor indication of the size of the increase in later years. It should be noted that with $\mathrm{Fe}$ (but not with the other elements), B is very small at two sites, so that the concentration practically does not change with $\mathrm{t}$.

\section{Continuously decreasing elements}

The concentrations of $\mathrm{Cl}, \mathrm{Cs}, \mathrm{Cu}, \mathrm{K}, \mathrm{Mg}, \mathrm{P}$, and $\mathrm{Rb}$ all show a decrease with increasing needle age. Examples are given in Table 1 for $\mathrm{K}, \mathrm{P}$ and $\mathrm{Rb}$, and in Figure 3 for Cs. The values approach asymptotically a constant

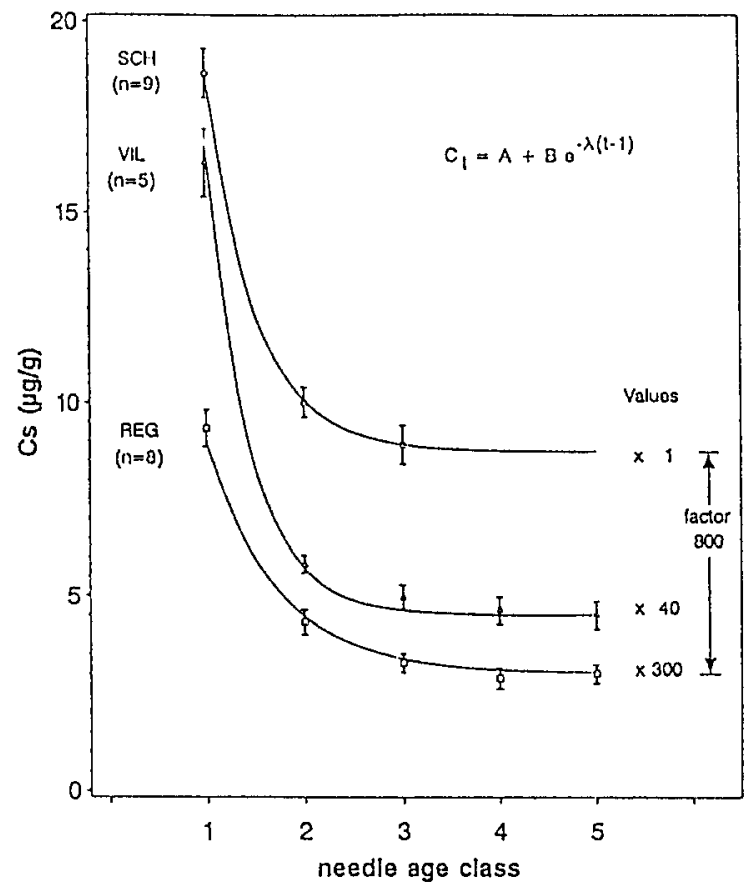

Fig. 3. Cs concentrations at the sites with the smallest and largest values and at an intermediate site. The curves are the fits to Equation 4. The constants were found to be for REG, VIL, SCH: A (ng g ${ }^{-1}$ ) 10, 113, 8700: $\mathrm{B}\left(\mathrm{ng} \mathrm{g}^{-1}\right) 20,300,9800 ; \lambda 1.4,2.3,2.0$. The mean deviation (experimental-predicted) is $3 \%$. All values for VIL have been multiplied by 40 and those for REG by 300 for an easier presentation

value. This behaviour is described by

$$
c_{t}=A+B \cdot e^{-\lambda(t-1)}
$$

Equation 4 contains a constant term (A, the value for a large $t)$ and a decreasing term $\left(B \cdot e^{-\lambda(t-1)}\right)$. The decreasing term denotes export or retranslocation. The amount available for export decreases each year by the same fraction (e). For age class 1 Equation 4 yields $c_{1}$ $=\mathrm{A}+\mathrm{B}$. The same type of function holds at all concentration levels (Fig. 3). Cs concentrations in a given age class vary widely, as well between individual trees at a given site as between different sites. Despite these large variations, the constants for Cs (and for $\mathrm{Rb}$ ) at the various sites show similar features.

\section{Elements which need more than one function}

$\mathrm{Mn}, \mathrm{Zn}$, and Co do not show an uniform behaviour in all trees. In some trees, the values decrease with $t$, in others they are more or less constant, and in some they increase. With $\mathrm{Zn}$ and $\mathrm{Co}$, more decreasing than increasing trees were found, whereas the opposite holds for $\mathrm{Mn}$. With $\mathrm{Zn}$, the type of function does not 


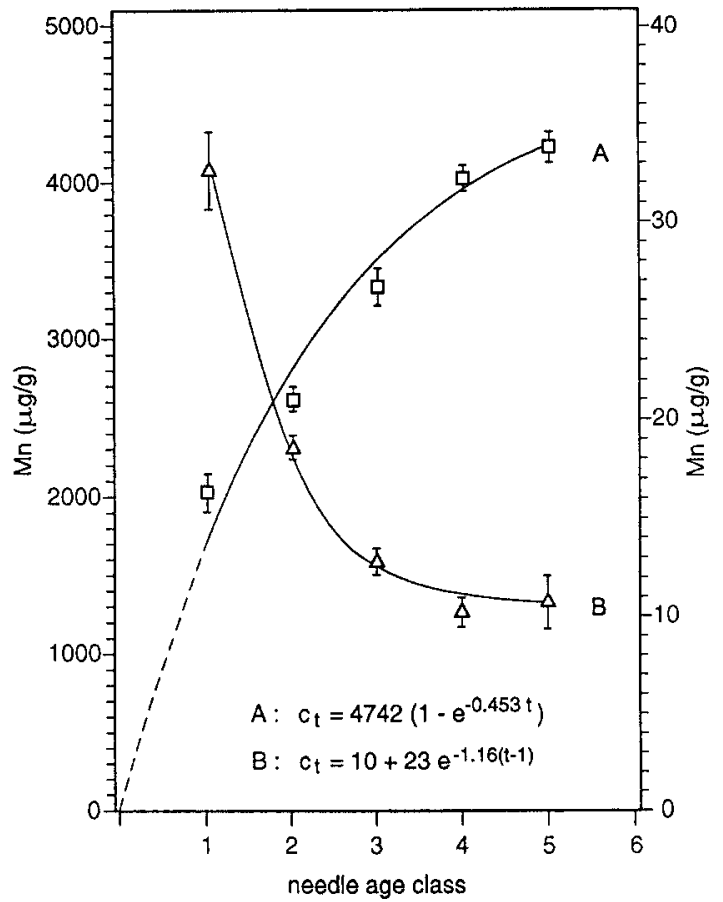

Fig. 4. Mn concentrations at the sites with the highest values (curve A, left scale, AUE, $n=8$ trees) and a subpoplation with low values (curve $B$, right scale, REG, $n=4$ trees). The curves are the fits to Equation 5 (curve A, mean deviation 10\%) and to Equation 4 (curve $B$, mean deviation $6 \%$ ).

depend on the concentration level. With Co, and most clearly with $\mathrm{Mn}$, there is a clear effect in the sense that small concentrations in age class 1 are connected with a decreasing function and high concentrations with an increasing function. Decreasing values of $\mathrm{Mn}$, $\mathrm{Co}$, and $\mathrm{Zn}$ in trees with small concentrations can well be described by Equation 4, whereas high $\mathrm{Mn}$ concentrations increase approaching asymptotically a constant value. Figure 4 gives 2 extreme cases for $\mathrm{Mn}$. The increasing curve for $\mathrm{Mn}$ (Fig. 4A) is given by

$$
c_{t}=A\left(1-e^{-\lambda t}\right)
$$

Equations of this type can formally be explained by an influx that is proportional to time and an outflux that is proportional to the accumulated mass.

Elements with a tendency towards an erratic behaviour At each site, $\mathrm{Mn}$ (if present at high concentrations) and $\mathrm{Ca}, \mathrm{Sr}$, and $\mathrm{Ba}$ (at all concentrations) show a similar dynamic behaviour. At some sites the changes can be approximated by Equation 5. At other sites, however, the values show an erratic behaviour in the sense that the concentrations do not follow a smooth increase, but show e.g. $c_{2}>c_{3}<c_{4}$. These irregularities usually are found in most trees at a site, and they are always shown by all 3 (or 4 ) elements. Therefore, in contrast to the individual elements, the ratio between any two (e.g. $\mathrm{Ba} / \mathrm{Ca}$ ) always follows smooth curves.

\section{Discussion}

The biodynamic behaviour of most elements can be described by smooth algebraic functions. Although with some of these functions the degree of freedom is small, the agreement between the experimental site means and the function is satisfactory. As may be seen from the figures, deviations are mostly explained by the (reduced) standard error of the experimental data.

Previous efforts to fit algebraic functions are scarce. Höhne (1963) used the function $c_{t}=A-B \cdot \log t(E q$. 6) to describe the decrease of $K$ and $P$ in spruce needles. Applying this function to the $\mathrm{K}$ data in Table 1 gives a root mean square error of $300 \mu \mathrm{g} \mathrm{g}^{-1}$, which is clearly in excess of the mean reduced standard error of the experimental data $\left(70 \mu \mathrm{g} \mathrm{g}^{-1}\right.$; moreover the residuals are distributed in a conspicuously non-random manner. Both results indicate an important lack-offit. Applying Equation 4 to the same data yields much better results (root MSE $45 \mu \mathrm{g} \mathrm{g}^{-1}$, residuals distributed randomly), and this function is therefore definitely more appropriate.

It should be noted that Equations 2 to 5 are defined only for integer values of $t$. Interpolation therefore should not be done. Extrapolation to $t=0$ does not make sense as there is no needle age class zero. In the figures, however, this extrapolation has been included for Equations 2, 3 and 5 in order to make the difference between the increasing functions clear. Needle weight was found not to differ substantially between age classes at a given site. The proposed equations, which are expressed on a concentration basis, will therefore, after the appropriate transformations, also be valid for the contents of a needle.

Although the biodynamic functions proposed here are empirical, they can in many instances be tentatively interpreted. Equation 2 is appropriate for elements whose accumulation is due to an uptake with the transpiration stream and an irreversible deposition in the needle (Raven, 1983; Wyttenbach et al., 1991). The accumulated mass per year is given by the yearly increment $B$. The yearly increments of the trace elements (except $\mathrm{Na}$ ) are of the order of $\mathrm{ng} \mathrm{g}^{-1}$ (Wyttenbach et al., 1994), and this is too small to form dis- 
crete deposits. It is therefore suggested that these trace elements are incorporated into the amorphous silica resulting from the much more important uptake of $\mathrm{Si}$, the yearly increment of which is about $1000 \mu \mathrm{g} \mathrm{g}^{-1}$. The biodynamic functions for $\mathrm{Sb}, \mathrm{Sc}$ and the rare earth elements are therefore related to the biomineralization of Si (Simkiss and Wilbur, 1989).

Equation 3 is appropriate for a situation where the uptake during the first year is much more pronounced than in later years. Fe shows this behaviour, due to its role as an essential element whose presence in the developing young needle is important. All site means for $\mathrm{c}_{1}$ are between 12 and $25 \mu \mathrm{g} \mathrm{g}^{-1}$; this is considerably less than is often considered (Anonymous, 1986) to be the optimal range for $\mathrm{Fe}$ in Norway spruce (30 $-180 \mu \mathrm{g} \mathrm{g}^{-1}$ ). Most sites are even below the critical deficiency level $\left(20 \mu \mathrm{g} \mathrm{g}^{-1}\right)$ without showing deficiency symptoms. This contradiction must be due to the fact that older values are mostly based on analyses that included the nonphysiological surface contaminations, whereas the present values are for endogenous concentrations only. Fe concentrations similar to those presented here are also found in Scots pine ( 24 and 29 $\mu \mathrm{g} \mathrm{g}^{-1}$ ), if the needles have been properly treated (Van Dijk and Bienfait, 1993). The argument of essentiality does not apply to the other elements of this group. It is suspected that the accumulation of $\mathrm{Hg}$ (Maserti and Ferrara, 1991), Br, I (Tobler et al., 1994), and possibly also As is mainly due to foliar uptake with subsequent irreversible binding. Figge (1990) has shown that some gaseous halogenated organic compounds are taken up rapidly through the cuticula. The observed increased accumulation during the first year might then be due to the greater permeability of the young needle. In later years the permeability and the uptake are reduced, but accumulation proceeds proportionally to the exposure time and therefore to $t$.

Equation 4 describes the behaviour of continuously decreasing elements $(\mathrm{K}, \mathrm{Rb}, \mathrm{Cs} ; \mathrm{Mg}, \mathrm{Cu} ; \mathrm{P}, \mathrm{Cl})$. They have the highest concentration in needles of age class 1 , i.e. in the needles with the highest physiological activity. Their decrease reflects the retranslocation between needles of different age classes, and the high mobility within the plant. The fact that these elements can be described by the same type of equation does not necessarily imply a constant ratio between any two of them. A constant ratio is expected only if the parameters of the equations for the two elements fulfill certain conditions (similar values for $\mathrm{A} / \mathrm{B}$ and for $\lambda$ ). At most sites these conditions are met for the pair $K$ and $P$. As an example, the $K$ values of Table 1 are larger than the corresponding $\mathrm{P}$ values by a constant factor of 4.70 with a CV of only $3 \%$ between the different age classes. This constancy is probably due to the fact that $\mathrm{K}^{+}$is present mostly as a counterion to P-containing anions. Contrasting with the constant ratio $\mathrm{K} / \mathrm{P}$ is the ratio $K / R b$, which increases at all sites with $t$. The $K$ values of Table 1 are larger than the corresponding $R b$ values by a factor of 1050 with $t=1$ and by 2160 with $t=5$, i.e. the ratio $K / R b$ increases by a factor of two. Considering the close chemical similarity of $\mathrm{K}$ and $\mathrm{Rb}$, this large shift is surprising. It is possible only because more than one compartment is involved in the storage (Schmidt et al., 1989); obviously the transitions between some compartments discriminate heavily between $\mathrm{K}$ and $\mathrm{Rb}$. These differences call into question the general usefulness of ${ }^{86} \mathrm{Rb}$ as a tracer for $\mathrm{K}$, as was also noted by van den Driessche (1991).

$\mathrm{Zn}$ decreases in most trees similarly to the mobile elements (Eq. 4). In a few trees, however, it increases strongly. This different behaviour was already noted by Fiedler (1988), who attributed decreasing $\mathrm{Zn}$ concentrations to insufficient supply.

The dynamic behaviour of $\mathrm{Mn}$ is remarkable for the fact that, when present at low concentrations (Fig. 4B), it decreases similarly to the highly mobile elements (Eq. 4), whereas at high concentrations (Fig. 4A) it increases approaching asymptotically a constant value (Eq. 5). The change in the dynamic behaviour occurs at about $c_{1}=100 \mu \mathrm{g} \mathrm{g}^{-1}$. Mn is probably deposited in the needle as $\mathrm{MnC}_{2} \mathrm{O}_{4} \cdot 2 \mathrm{H}_{2} \mathrm{O}$, similar to the deposition of $\mathrm{Ca}$ as $\mathrm{CaC}_{2} \mathrm{O}_{4} \cdot 1 \mathrm{H}_{2} \mathrm{O}$. This is corroborated by the observation that at AUE, where $\mathrm{Mn}$ concentrations are high, the dynamic behaviour of $\mathrm{Ca}$ and $\mathrm{Mn}$ are very similar; the ratio $\mathrm{Ca} / \mathrm{Mn}$ has a constant value of 2.0 with a CV of only $3 \%$ between the different age classes. These remarkably similar dynamics of $\mathrm{Mn}$ (at high concentrations) and of $\mathrm{Ca}$ have also been noted for the changes that occur within one season (Kazda and Zvacek, 1989). However, since the solubility of Mnoxalate $\left(260 \mathrm{mg} \mathrm{L}^{-1}\right)$ is much greater than that of Ca-oxalate $\left(6 \mathrm{mg} \mathrm{L}^{-1}\right)$, the precipitation of $\mathrm{Mn}$ at low needle concentrations is not possible, and Mn stays mobile. That the high mobility of Mn at REG is not due to a lack of oxalate is shown by the Ca concentrations, which at that site have values and a dynamic behaviour very similar to that at AUE.

It is known that $\mathrm{Ca}$ in the needle is distributed among different pools, the most important always being Ca-oxalate (Fink, 1991), which is precipitated to regulate the concentration of soluble $\mathrm{Ca}$. The similar dynamic behaviour of $\mathrm{Ca}, \mathrm{Sr}, \mathrm{Ba}$, and $\mathrm{Mn}$ (at high 


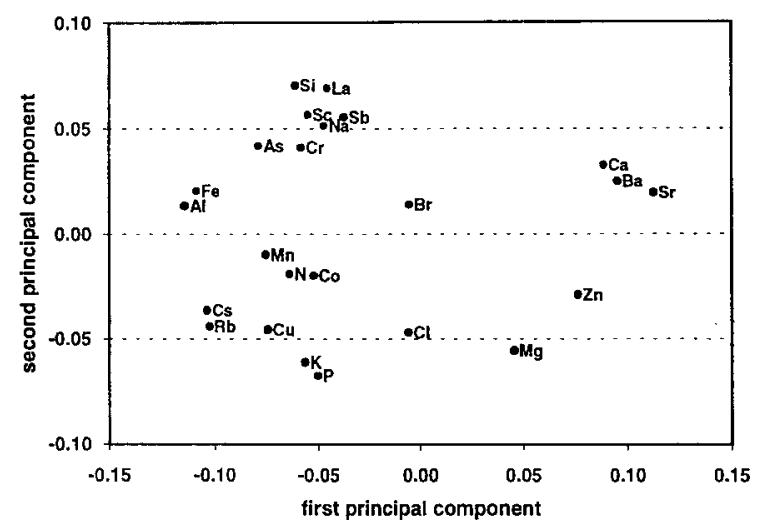

Fig. 5. Principal components calculated on the logarithms of the elemental concentrations. Component 1 reflects differences between sites and accounts for $36 \%$ of the total variance. Component 2 is related to the increase or decrease of concentrations with the needle age classes (see text); it accounts for $21 \%$ of the variance

concentrations) suggests that all 3 (or 4) elements participate in the deposition of the oxalates. However, the ratio between two alkaline earth metals is not constant with $\mathrm{t}$. The ratio $\mathrm{Sr} / \mathrm{Ca}$ diminishes at all sites by about a factor of 1.2 between age classes 1 and 5 , and the ratio $\mathrm{Ba} / \mathrm{Ca}$ by the larger factor of 1.5 . This may be due to the different solubilities if individual oxalates are formed, or to fractionation effects if mixed oxalates are formed. The cause for the erratic behaviour of $\mathrm{Ca}$, $\mathrm{Sr}, \mathrm{Ba}$ and $\mathrm{Mn}$ found at some sites is not clear. One possibility is that the uptake, which occurs mainly in age class 1 , is slightly different from year to year, and that these differences are preserved in later years.

A general picture of the relations between the various elements can be obtained by multivariate statistics. An analysis of the principal components (Fig. 5) has been applied to our data (except for $\mathrm{Hg}$ and I, because of missing values).

The first component has been interpreted as an effect of the different sites from which samples were collected. The second component is clearly related to time, i.e. to the needle age classes. Negative values indicate decreasing concentrations, positive values increasing ones.

Elements that can be described by Equation 4 (asymptotic decrease) are indeed at the bottom of the plot, while those following Equation 2 (linear increase) appear at the top. Elements fitted by Equation 3 or 5 (linear increase with a constant term, or asymptotic increase) have moderately positive values. Finally, elements with small $(\mathrm{N})$ or inconsistent changes $(\mathrm{Mn}$, $\mathrm{Co}, \mathrm{Zn}$ ) show up slightly below zero.
The distances between pairs of elements in Figure 5 is a measure of how differently they vary. These differences arise either from the sites (component 1) or from the age classes (component 2). Although some elements appear to be clustered according to their chemical similarities, neither their position in the periodic system, nor the grouping according to their covalent and ionic indexes (Woolhouse, 1983), gives a satisfactory coincidence with Figure 5. Neither system is able to predict the incongruencies shown here: $\mathrm{K}, \mathrm{Rb}$, $\mathrm{Cs} \neq \mathrm{Na}$; $\mathrm{Ca}, \mathrm{Sr}, \mathrm{Ba} \neq \mathrm{Mg} ; \mathrm{Fe} \neq \mathrm{Co} \neq \mathrm{Cu} ; \mathrm{Cl} \neq$ $\mathrm{Br}$ and $\mathrm{P} \neq \mathrm{As}$. These examples point to the fact that the involved biochemical processes are very intricate, and that much more work needs to be done for a satisfactory understanding of the biodynamic curves of the individual elements.

\section{Acknowledgements}

We want to thank the staff of the Saphir reactor (PSI) for providing irradiation facilities. The skill-full experimental help of Mrs V Furrer and Mrs S Brütsch is highly appreciated. The work was partially supported by the Swiss National Science Foundation (grant 31-30755.91).

\section{References}

Anonymous 1986 Forschungsbeirat Waldschäden/ Luftverunreinigungen, 2. Bericht, KfK Karlsruhe, Germany. pp 87-116.

Cape J N, Freer P H, Paterson I S, Parkinson J A and Wolfenden J 1990 The nutritional status of Picea abies (L.) Karst. across Europe. Trees 4, 211-224.

Fiedler H 1988 Zur Zinkausstattung der Fichtenökosysteme in Gebieten mit neuartigen Waldschäden. Beitr. Forstwirtschaft 22, 6166.

Fiedler H, Nebe W and Hoffmann F 1973 Forstliche Pflanzenernährung und Düngung. Fischer, Jena, Germany. 481 p.

Figge K 1990 Luftgetragene, organische Stoffe in Blattorganen. Z. Umweltchem. Ökotox. 2, 200-207.

Fink S 1991 The micromorphological distribution of bound calcium in needles of Norway spruce [Picea abies (L.) Karst.]. New Phytol. 119, 33-40.

Höhne H 1963 Blattanalytische Untersuchungen an jüngeren Fichtenbeständen. Arch. Forstwese. 12, 341-360.

Kazda M and Zvacek L 1989 Aluminium and manganese and their relation to calcium in soil solution and needles in three Norway spruce (Picea abies, L. Karst.) stands of Upper Austria. Plant and Soil 114, 257-267.

Mahendrappa M K, Foster N W, Weetman G F and Krause H H 1986 Nutrient cycling and availability in forest soils. Can. J. Soil Sci. $66,547-572$

Maserti B E and Ferrara R 1991 Mercury in plants, soil and atmosphere. Water Air Soil Pollut. 56, 15-20. 
Raven J 1983 The transport and function of silicon in plants. Biol, Rev. 58, 179-207.

Schmidt R, Lüttge U and Kramer D 1989 Supply and compartmentalization of potassium in mesophyll cells of the needles of spruce. Trees 3, 154-160.

Simkiss K and Wilbur KM 1989 Biomineralization. Academic Press, San Diego. $117 \mathrm{p}$.

Tobler L, Bajo S, Wyttenbach A and Langenauer M 1994 Bromine and iodine in the system aerosol-plant. Fresenius J. Anal. Chem. (In press).

Van Dijk H F G and Bienfait H F 1993 Iron-deficiency chlorosis in Scots pine growing on acid soils. Plant and Soil 153, 255-263.

Van den Driessche R 1991 Mineral nutrition of conifer seedlings. CRC, Boca Raton, USA. 36 p.

Woolhouse H W 1983 Toxicity and tolerance in the responses of plants to metals. Encycl. Plant Physiol. 12C, 245-300.
Wyttenbach A, Tobler L and Bajo S 1991 Silicon concentrations in spruce needles. Z. Pflanzenernähr. Bodenkd, 154, 253-258.

Wyttenbach A, Bajo S, Tobler L, Adam M and Zöttl H W 1992 Elemental concentrations in spruce needles. In Applications of isotopes and radiation in conservation of the environment. IAEASM-325. pp. 535-546. International Atomic Energy Agency, Vienna, Austria.

Wyttenbach A, Schleppi P, Bucher J, Furrer V and Tobler L 1994 The accumulation of the rare earth elements and of scandium in successive needle age classes of Norway spruce. Biol. Trace Elem. Res. 41, 13-29. 